\title{
Kinerja Lembaga Perkreditan Desa (LPD) Adat Demayu Desa Singakerta Kecamatan Ubud Kabupaten Gianyar
}

\author{
NI MADE MITA SINTYA PRADNYANI, I KETUT SUAMBA, \\ I GUSTI AA LIES ANGGRENI
}

Program Studi Agribisnis, Fakultas Pertanian, Universitas Udayana

J1 PB. Sudirman Denpasar 80323

Email: mitta_sintya@yahoo.com

suamba_unud@yahoo.co.id

\begin{abstract}
Performance of Village Credit Instituion (LPD) of Demayu Singakerta Village Ubud District Gianyar Regency
\end{abstract}

The Village Credit Institution (LPD) of Demayu is an institution that plays a role in the economy of the Indigenous Village of Demayu and as one of the financial institutions in rural agriculture. The development and progress of Village Credit Institutions can be seen through some of the performance namely the financial and the management performances. The purpose of the study was to determine the financial performance by using the profit-oriented ratio of financial institutions and the management performance of the Village Credit Institution (LPD) of Demayu in terms of internal and external aspects. The analytical method used to assess the financial performance was conducted by using profit-oriented ratio analysis of financial institutions while the assessment of the management performance can be seen from two aspects, i.e. the internal and the external performances. Internal performance can be analyzed from the employee satisfaction aspect and the external performance can be seen from the customer satisfaction aspect as measured by Likert scale. Based on the findings of the research, it can be concluded that the Village Credit Institution (LPD) of Demayu financial performance evaluated from current ratio, debt to asset ratio, total asset turnover were in very unfit category, while the net profit margin was fit. The management performance in terms of internal aspect obtained an overall average score of 3,97\% that categorized as satisfied while the performance of management in terms of external aspects obtained an overall average score of $4.09 \%$ that is also categorized as satisfied . Suggestions that can be given: the Village Credit Institution (LPD) of Demayu should further foster their own capital so that assets increase without increasing the debt; one of them is by way of increasing credit distribution activities to the community, for performance management in terms of internal aspects, the management should more often communicate and interact with employees, for the management performance viewed from the external aspect, the management should pay more attention and improve the quality of service, and every activity carried out on the Village Credit Institution (LPD) of Demayu should be more emphasized on the concept of Tri Hita Karana.

Keywords: Village credit institution, financial performance, ratio analysis 


\section{Pendahuluan}

\subsection{Latar Belakang}

Bali merupakan salah satu provinsi di Indonesia yang terkenal dengan kebudayaannya, salah satu keunikan di Bali adalah eksistensi dari desa pakraman. Adapun lembaga yang berperan dalam perekonomian desa pakraman dan juga sebagai salah satu lembaga keuangan pertanian di desa adalah Lembaga Perkreditan Desa (LPD) yang berfungsi dan bertujuan utama untuk mendorong pembangunan ekonomi masyarakat, baik dalam hal pertanian maupun non pertanian melalui tabungan yang terarah serta penyaluran modal yang efektif. Lembaga Perkreditan Desa (LPD) mempunyai peran sebagai lembaga yang berperan untuk meningkatkan kesejahteraan rakyat melalui pembangunan ekonomi kerakyatan, dan juga sebagai sumber pendapatan asli Desa Adat, karena dalam Peraturan Daerah Provinsi Bali No.4 Tahun 2012 tentang LPD pasal 22 ayat 1 menjelaskan bahwa salah satu pembagian keuntungan bersih LPD pada akhir tahun pembukuan adalah untuk dana pembangunan desa $20 \%$ dan dana sosial 5\%. Pengungkapan tanggung jawab sosial pada LPD di Bali menunjukkan seberapa besar kontribusi yang diberikan LPD pada masyarakat desa adat sesuai dalam ajaran Tri Hita Karana, yang terdiri atas parhyangan, pawongan, dan palemahan, semakin berkembang dan majunya Lembaga Perkreditan Desa (LPD) maka semakin besar keuntungan yang diperoleh Lembaga Perkreditan Desa (LPD) itu sendiri, untuk menciptakan hal tersebut suatu Lembaga Perkreditan Desa (LPD) harus memiliki kinerja yang baik dalam menjalankan setiap kegiatannya. Kinerja merupakan hasil kerja baik secara kualitas dan kuantitas yang dicapai oleh suatu lembaga atau seseorang dalam melaksanakan tugas sesuai dengan tanggung jawab yang diberikan kepadanya (Mangkunagara, 2002). Perkembangan dan kemajuan suatu Lembaga Perkreditan Desa (LPD) dapat dilihat melalui beberapa kinerja yang diantaranya yaitu kinerja keuangan dan kinerja manajemen.

Lembaga perkreditan Desa (LPD) Adat Demayu merupakan Lembaga perkreditan Desa (LPD) yang dikelola oleh Desa Adat Demayu yang terdiri atas lima banjar. Ditinjau dari perkembangan Lembaga Perkreditan Desa (LPD) Adat Demayu sudah cukup baik tetapi masih banyak hal yang perlu ditingkatkan. Lembaga Perkreditan Desa (LPD) Adat Demayu ingin meningkatkan kinerjanya agar dapat bersaing dengan lembaga keuangan lainnya baik dalam hal finansial, pelayanan nasabah, dan dalam hal meningkatkan jumlah nasabah, karena sampai saat ini Lembaga Perkreditan Desa (LPD) Adat Demayu dalam hal finansial masih berfokus pada neraca dan laporan laba rugi saja, dan ditinjau dari aspek nasabah adanya beberapa masalah terutama dibidang kredit sehingga peranan karyawan dalam hal ini untuk membujuk nasabah agar membayar hutang sangat diperlukan.

Hal tersebut merupakan masalah yang dihadapi oleh Lembaga Perkreditan Desa (LPD) Adat Demayu saat ini, adapun data perkembangan laba dan asset Lembaga Perkreditan Desa (LPD) Adat Demayu periode tahun 2011 s/d 2016 disajikan pada Tabel 1 sebagai berikut. 
Tabel 1.

Perkembangan Laba dan Asset LPD Adat Demayu periode Tahun 2011 s/d 2016

\begin{tabular}{ccr}
\hline TAHUN & LABA & \multicolumn{1}{c}{ ASSET } \\
\hline 2011 & Rp.260.336.686,00 & Rp.9.869.390.798,00 \\
2012 & Rp.340.792.600,00 & Rp. $13.507 .813 .798,00$ \\
2013 & Rp. $417.427 .800,00$ & Rp. $18.940 .231 .598,00$ \\
2014 & Rp. $554.237 .100,00$ & Rp. $23.463 .708 .898,00$ \\
2015 & Rp.707.577.016,00 & Rp.28.016.234.782,00 \\
2016 & Rp.735.873.735,00 & Rp.32.197.450.682,00 \\
\hline
\end{tabular}

Sumber: Lembaga Perkreditan Desa (LPD) Adat Demayu (2016)

Berdasarkan data perkembangan laba dan assetLPD Adat Demayu periode tahun 2011 sampai dengan 2016 pada Tabel 1 cenderung mengalami peningkatan setiap tahunnya, akan tetapi analisis terhadap laporan keuangan atau analisis mengenai rasio keuangan harus tetap dilaksanakan, dalam hal ini penulis menggunakan rasio-rasio lembaga keuangan yang lebih berorientasi pada keuntungan (profit oriented), dengan tujuan untuk mendukung kinerja LPD yang lebih berorientasi pada manfaat (benefit oriented), dan sangat berguna untuk mengetahui pencapaian yang diperoleh perusahaan, digunakan untuk mengevaluasi kondisi keuangan, serta dapat meningkatkan kinerja keuangan LPD Adat Demayu, namun seiring berkembangnya zaman perkembangan finansial saja tidak cukup untuk menilai kinerja suatu badan usaha, sehingga kita juga harus menilai dari aspek manajemen yang diterapkan, agar pihak-pihak yang berkepentingan dapat mengambil keputusan secara cermat mengingat masalah yang dihadapi oleh Lembaga Perkreditan Desa (LPD) Adat Demayu.

Analisis kinerja keuangan dengan menggunakan rasio-rasio lembaga keuangan yang berorientasi pada profit (profit oriented) dan kinerja manajemen yang ditinjau dari aspek intenal dan aspek eksternal dalam penelitian ini diharapkan mampu untuk menilai dan meningkatkan kinerja Lembaga Perkreditan Desa (LPD) Adat Demayu sehingga nantinya bisa lebih bersaing dengan lembaga keuangan atau Lembaga Perkreditan Desa (LPD) lainnya serta dapat lebih berkembang dan maju.

\subsection{Tujuan Penelitian}

Berdasarkan rumusan masalah yang tertera di atas, maka tujuan dari penelitian ini untuk mengetahui ;

1. Kinerja keuangan LPD Adat Demayu menggunakan analisis rasio lembaga keuangan yang berorientasi pada profit (profit oriented).

2. Kinerja manajemen LPD Adat Demayu yang ditinjau dari aspek internal dan eksternal. 


\subsection{Kinerja Perusahaan}

Kinerja merupakan hasil karya secara kualitas dan kuantitas yang dicapai seseorang dalammelakukan tugasnya sesuai dengan tanggungjawab yang diberikan kepadanyaRivai dalam Sagala (2006). Menganalisis kinerja keuangan suatu lembaga atau perusahaan, analisis rasio keuangan merupakan alat utama dalam menganalisis kinerja keuangan, karena analisis ini dapat digunakan untuk menjawab berbagaipertanyaan tentang keadaan keuangan perusahaan. Terdapat empat rasio yang dapat digunakan dalam menganalisis kinerja keuangan suatu perusahaan yaitu rasio likuiditas, solvabilitas, aktivitas, dan profitabilitas, sedangkan untuk menganalisis kinerja manajemen dapat dilihat dari kinerja internal dan kinerja eksternal suatu perusahaan. Kinerja internal merupakan kinerja yang dilihat dari dalam suatu perusahaan, pada penelitian ini kinerja internal dilihat dari aspek tingkat kepuasan kerja karyawan, sedangkan kinerja ekternal merupakan kinerja yang dilihat dari luar suatu perusahaan, dalam penelitian ini kinerja ekternal dilihat dari aspek tingkat kepuasan pelanggan atau nasabah Lembaga Perkreditan Desa Adat Demayu.

\section{Metode Penelitian}

\subsection{Lokasi dan Waktu Penelitian}

Penelitian ini dilakukan di Lembaga Perkreditan Desa (LPD) Adat Demayu yang berlokasi di Br. Demayu Lodtunduh, Desa Singakerta, Kecamatan Ubud, Kabupaten Gianyar. Pelaksanaan waktu penelitian ini dilakukan mulai Desember 2016 sampai Februari 2017. Pemilihan lokasi ini dilakukan dengan metode purposive, yaitu pemilihan lokasi penelitian secara sengaja (Sugiyono, 2010), didasarkan atas pertimbangan-pertimbangan yaitu (1) LPD Adat Demayumenjalankan usahanyaselama 22 tahun dan sampai saat ini masih tetap berjalan, (2) unit usahanya masih menggunakan tolak ukur yang hanya berfokus pada kinerja keuangan, (3) pihak manajemen bersikap terbukasehingga data yang diperlukan dalam penelitian mudah diperoleh, (4) belum pernah dilakukan penelitian yang sama dan (5) LPD Adat Demayu juga berfungsi sebagai lembaga keuangan pertanian karena sebagaian besar masyarakat berprofesi sebagai petani.

\subsection{Metode Pengumpulan Data dan Variabel Penelitian}

Studi dokumen dilakukan untuk mendapatkan laporan laba-rugi, dan neraca LPD Adat Demayu dari tahun 2011 sampai dengan tahun 2016, sedangkan untuk mendapatkan data tingkat kepuasan karyawan dan nasabah dilakukan melalui metode wawancara dengan berpedoman pada kuesioner yang dipersiapkan sebelumnya. Variabel-variabel yang dianalisis adalah (1) Kinerja keuangan dengan indikator yaitu Rasio Likuiditas, Rasio Solvabilitas, Rasio Profitabilitas, Rasio Aktivitas dan (2) Kinerja manajemen dengan indikator yaitu kepuasan karyawan dan kepuasan nasabah. 


\subsection{Penentuan Sampel dan Teknik Pengambilan Sampel}

Sampel karyawan yang digunakan dalam penelitian ini sebanyak 15 orang yang merupakan seluruh karyawan LPD Adat Demayu, dan untuk pemilihan sampel nasabah dilakukan secara sengaja dengan mengambil 10 sampel dari setiap kelompok, sehingga jumlah sampel nasabah yang akan diwawancarai sebanyak 30 orang dengan pertimbangan jumlah tersebut sudah memenuhi sebaran normal dan merupakan jumlah sampel minimal dalam statistik. Sakara (2006) menyatakan bahwa ukuran sampel minimal atau lebih besar dari 30 dan kurang dari 500 adalah tepat untuk hampir semua penelitian.

\subsection{Metode Analisis Data}

Adapun metode analisis yang digunakan dalam penelitian ini sebagai berikut.

1. Penilaian kinerja keuangan,

Anaisis yang digunakan untuk menjawab rumusan masalah yang pertama yaitu analisi rasio keuangan lembaga yang berorintasi pada keuntungan (profit oriented), adapun bagian-bagian dari analisis rasio keuangan yang digunakan yaitu sebagai berikut.

i. Rasio likuiditas :

Current ratio $\quad=\frac{\text { Aktiva lancar }}{\text { Hutang lancar }} \times 100 \% \ldots \ldots \ldots \ldots \ldots \ldots \ldots \ldots$

ii. Rasio solvabilitas :

Total hutang

Debt to assets ratio $=\frac{T}{\text { Total aktiva }} \times 100 \% \ldots \ldots \ldots \ldots \ldots \ldots \ldots \ldots \ldots$

iii.Rasio aktvitas :

Pendapatan

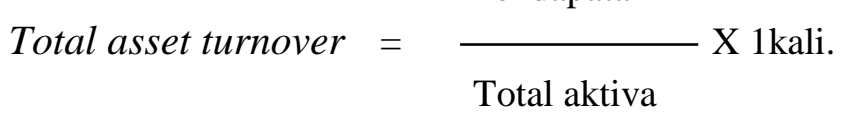

iv. Rasio Profitabilis :

Laba bersih

Net profit margin $=\frac{}{\text { Pendapatan }} \times 100 \%$

Adapun standar pengukuran rasio likuiditas, rasio solvabilitas,rasio aktivitas, dan rasio profitabilitas berdasarkan peraturan menteri Koperasi dan UKM Republik Indonesia Nomor 06/Per/M.KUKM/V/2006 tanggal 1 Mei 2006 tentang pedoman penilaian kinerja keuangan. 


\section{Penilaian Kinerja Manajemen}

Analisis yang digunakan untuk menjawab rumusan masalah yang kedua mengenai tingkat kepuasan nasabah dan karyawan diukur menggunakan skala likert. Analisis ini dihasilkan dari penilaian jawaban kuesioner, dimana setiap jawabannya telah diberi bobot tertentu. Setiap jawaban akan dikelompokkan lalu ditabulasikan dan kemudian dijumlahkan sehingga dapat diketahui skor total dari seluruh responden. Skala likert digunakan untuk mengukur sikap, pendapat, dan persepsi seseorang tentang suatu objek atau fenomena tertentu (Siregar, 2011), dengan skala ini responden diminta menjawab setiap pernyataan dengan memilih satu dari lima pilihan dimana 1 (satu)menunjukan tingkat yang paling rendah dan 5 (lima) menunjukan tingkat yang paling tinggi. Ketentuan yang dipakai untuk menilai kisaran skor dapat dirumuskan oleh Effendi dan Singarimbun (1989) sebagai berikut.

$$
I=\frac{\text { Jarak }}{\text { Jumlah Kelas }}=\frac{5-1}{5}=0,8
$$

Dimana :

I : Interval kelas

Jarak : Nilai data tertinggi dikurangi nilai data terendah

Jumlah kelas : Jumlah kategori yang ditentukan

Interval kelas diatas digunakan untuk mengetahui nilai masing-masing kelas. Nilai dari masing-masing kelas diformulasikandengan menggunakan skor. Kategori ini dapat dilihat pada Tabel 2.sebagai berikut.

Tabel 2.

Katagori Tingkat Kepuasan Nasabah dan Karyawan LPD Adat Demayu

\begin{tabular}{ccc}
\hline Skor & Interval Skor & Katagori \\
\hline 1 & $1 \mathrm{~s} / \mathrm{d}<0,8$ & Sangat tidak puas \\
2 & $0,8 \mathrm{~s} / \mathrm{d}<2,6$ & Tidak puas \\
3 & $2,6 \mathrm{~s} / \mathrm{d}<3,4$ & Cukup puas \\
4 & $3,4 \mathrm{~s} / \mathrm{d}<4,2$ & Puas \\
5 & $4,2 \mathrm{~s} / \mathrm{d}<5$ & Sangat puas \\
\hline
\end{tabular}

\section{Hasil dan Pembahasan}

\subsection{Kinerja Keuangan}

Menurut Riyanto (1997), dalam mengadakan interpretasi dan analisis laporan finansial suatu perusahaan, seorang penganalisis finansial memerlukan adanya ukuran atau "yard-stick" tertentu. Ukuran yang sering digunakan dalam analisis finansial adalah "rasio", dalam penelitian ini menggunakan 4 jenis rasio, adapun hasil perhitingannya sebagai berikut. 
1. Hasil perhitungan current ratio dapat dilihat pada Tabel 3.

Tabel 3.

Current RatioLPD Adat Demayu Tahun 2011-2016

\begin{tabular}{|c|c|c|c|c|}
\hline Tahun & Aktiva Lancar & Hutang Lancar & Curent Ratio (\%) & Naik/Turun \\
\hline$(1)$ & $(2)$ & $(3)$ & (4) & $(5)$ \\
\hline 2011 & $8,366,196,673$ & $7,391,521,150$ & 113,19 & - \\
\hline 2012 & $11,470,669,773$ & $10,287,337,136$ & 111,50 & Turun \\
\hline 2013 & $16,273,501,473$ & $14,617,358,136$ & 110,92 & Turun \\
\hline 2014 & $19,967,626,773$ & $17,997,817,436$ & 110,94 & Naik \\
\hline 2015 & $23,964,085,773$ & $21,311.795,220$ & 112,45 & Naik \\
\hline 2016 & $27,535,863,592$ & $24,578,230,104$ & 112,03 & Turun \\
\hline & Rata-Rata & & $111,84 \%$ & $\begin{array}{c}\text { Sangat tidak } \\
\text { sehat }\end{array}$ \\
\hline
\end{tabular}

Sumber: Perhitungan current ratio

2. Hasil perhitungan debt to assets ratio dapat dilihat pada Tabel 4.

Tabel 4.

Debt to Assets Ratio LPD Adat Demayu Tahun 2011-2016

\begin{tabular}{ccccc}
\hline Tahun & Total Hutang & Total Aktiva & $\begin{array}{c}\text { Debt to assets } \\
\text { ratio }(\%)\end{array}$ & Naik/Turun \\
\hline$(1)$ & $(2)$ & $(3)$ & $(4)$ & $(5)$ \\
\hline 2011 & $7,391,521,150$ & $8,566,966,848$ & 86,28 & - \\
2012 & $10,287,337,136$ & $11,764,440,748$ & 87,44 & Naik \\
2013 & $14,617,358,136$ & $16,510,272,448$ & 88,86 & Naik \\
2014 & $17,997,817,436$ & $20,308,997,748$ & 88,62 & Turun \\
2015 & $21,311.795,220$ & $24,224,857,748$ & 87,97 & Turun \\
2016 & $24,578,230,104$ & $28,064,135,567$ & 87,58 & Turun \\
\hline & Rata-Rata & & 87,79 & Sangat tidak \\
& & & sehat \\
\hline
\end{tabular}

Sumber: Perhitungan debt to assets ratio

3. Hasil perhitungan total asset turnover dapat dilihat pada tabel 5 .

Tabel 5.

Total Asset Turnover LPD Adat Demayu Tahun 2011-2016

\begin{tabular}{ccccc}
\hline Tahun & Pendapatan & Total Aktiva & $\begin{array}{c}\text { Total asset } \\
\text { turnover }(\text { kali })\end{array}$ & Naik/Turun \\
\hline$(1)$ & $(2)$ & $(3)$ & $(4)$ & $(5)$ \\
\hline 2011 & $1,474,420,886$ & $8,566,966,848$ & 0,172 & - \\
2012 & $1,945,825,900$ & $11,764,440,748$ & 0,165 & Turun \\
2013 & $2,652,047,200$ & $16,510,272,448$ & 0,161 & Turun \\
2014 & $3,418,108,500$ & $20,308,997,748$ & 0,168 & Naik \\
2015 & $4,096,114,300$ & $24,224,857,748$ & 0,169 & Naik \\
2016 & $4,358,349,100$ & $28,064,135,567$ & 0,155 & Turun \\
\hline & Rata-Rata & & 0,165 & Sangat tidak \\
& & & sehat \\
\hline
\end{tabular}

Sumber: Perhitungan total asset turnover 
4. Hasil perhitungan net profit margin dapat dilihat pada Tabel 6.

Tabel 6.

Net profit margin LPD Adat Demayu Tahun 2011-2016

\begin{tabular}{ccccc}
\hline Tahun & Laba & Pendapatan & $\begin{array}{c}\text { Net profit margin } \\
(\%)\end{array}$ & Naik/Turun \\
\hline$(1)$ & $(2)$ & $(3)$ & $(4)$ & $(5)$ \\
\hline 2011 & $260,336,686$ & $1,474,420,886$ & 17,66 & - \\
2012 & $340,792,600$ & $1,945,825,900$ & 17,51 & Turun \\
2013 & $417,427,800$ & $2,652,047,200$ & 15,74 & Turun \\
2014 & $554,237,100$ & $3,418,108,500$ & 16,21 & Naik \\
2015 & $707,577,016$ & $4,096,114,300$ & 17,27 & Naik \\
2016 & $735,873,735$ & $4,358,349,100$ & 16,88 & Turun \\
\hline \multicolumn{7}{c}{} & 16,88 & Sehat \\
\hline
\end{tabular}

Sumber: Perhitungan debt to assets ratio

Pada penelitian ini rasio-rasio yang digunakan merupakan rasio-rasio lembaga keuangan yang berorientasi pada keuntungan, dilihat dari hasil perhitungan current ratio menunjukkan hasil rata-rata current ratio sebesar $111,84 \%$ yang berada pada standart current ratio $<125 \%$ sehingga termasuk dalam kriteria sangat tidak sehat karena berada dibawah criteria lembaga keuangan yang berorientasi pada keuntungan (profit oriented), rasio likuiditas yang sehat dengan current ratio sebesar $200 \%$ s/d $250 \%$, pada hasil perhitungan total debt to asset ratio diperoleh nilai rata-rata sebesar $87,79 \%$ yangberada pada standart debt ratio $>80 \%$ sehingga termasuk dalamkriteria sangat tidak sehat karena berada diatas kriteria lembaga keuangan yang berorientasi pada keuntungan (profit oriented), rasio solvabilitas yang sehat dengan debt ratio < $40 \%$, dari perhitungan total asset turnover diperoleh nilai rata-rata sebesar 0,165 kali yang berada pada standard total asset turnover <1 kali sehingga termasuk dalam criteria sangat tidak sehat karena berada dibawah kriteria lembaga keuangan yang berorientasi pada keuntungan (profit oriented), rasio aktivitas yang sehat dengan total asset turn over 3,5 kali, dan dari perhitungan nett profit margin diperoleh nilai rata-rata net profit margin sebesar $16,88 \%$ yang berada pada standard net profit margin $>15 \%$ sehingga termasuk dalam kriteri sehat.

\subsection{Kinerja Manajemen}

Menurut Bacaal (2001), kinerja manajemen merupakan sebuah proses yang berkesinambungan dan dilakukan dengan kemitraan antara seorang karyawan dengan atasan, dalam penelitian ini kinerja manajemen dilihat dari aspek internal dan aspek eksternal. Aspek internal LPD Adat Demayu dinilai dari tingkat kepuasan karyawan dalam lima buah pernyataan yaitu kerja secara mental, gaji/imbalan, kondisi kerja, rekan kerja, dan kesesuaian kepribadian dengan pekerjaan, serta dalam satu pernyataan terdapat lima buah pertanyaan. Adapun hasil skor rata-rata dari pernyataan kerja secara mental yaitu sebesar 3,37\% yang termasuk kedalam katagori 
cukup puas, skor rata-rata dari pernyataan gaji/imbalan sebesar 4,09\% yang termasuk kedalam katagori puas, skor rata-rata dari pernyataan kondisi kerja sebesar 4,24\% yang termasuk kedalam katagori sangat puas, skor rata-rata dari pernyataan rekan kerja sebesar 4,01\% yang termasuk kedalam katagori puas, dan skor rata-rata dari pernyataan kesesuaian kepribadian dengan pekerjaan sebesar $4,12 \%$ yang termasuk kedalam katagori puas. Nilai skor rata-rata keseluruhan untuk tingkat kepuasan karyawan sebesar 3,97\% yang termasuk kedalam katagori puas.

Aspek eksternal LPD Adat Demayu dinilai dari tingkat kepuasan karyawan dalam lima buah pernyataan yaitu sarana fisik, keandalan, daya tanggap, jaminan, dan empati, serta dalam satu pernyataan terdapat lima buah pertanyaan. Adapun hasil skor rata-rata dari pernyataan sarana fisik yaitu sebesar 4,42\% yang termasuk kedalam katagori sangat puas, skor rata-rata dari pernyataan kendalan yaitu sebesar $4,11 \%$ yang termasuk kedalam katagori puas, skor rata-rata dari pernyataan daya tanggap yaitu sebesar 3,39\% yang termasuk kedalam katagori cukup puas, skor ratarata dari pernyataan jaminan yaitu sebesar $4,37 \%$ yang termasuk kedalam katagori sangat puas, dan skor rata-rata dari pernyataan empati yaitu sebesar 4,16\% yang termasuk kedalam katagori puas. Nilai skor rata-rata keseluruhan untuk tingkat kepuasan nasabah sebesar 4,09\% yang termasuk kedalam katagori puas.

\section{Simpulan dan Saran}

\subsection{Simpulan}

Berdasarkan hasil penelitian dan pembahasan, dapat ditarik suatu kesimpulan sebagai berikut.

1. Kinerja keuangan LPD Adat Demayu tahun 2011 s/d tahun 2016 menggunakan analisis rasio lembaga keuangan yang berorientasi pada keuntungan (profit oriented), untuk rasio profitabilitas berada pada standard net profit margin $>15 \%$ sehingga termasuk dalam kriteria sehat, rasio likuiditas berada pada standart current ratio $<125 \%$, rasio solvabilitas berada pada standart total debt to asset ratio $>80 \%$, dan rasio aktivitas berada pada standard total asset turnover $<1$ kali, sehingga ketiga rasio ini tergolong kedalam kriteria sangat tidak sehat, tetapi hal tersebut tidak menjadi masalah untuk LPD adat demayu karena LPD adat Demayu masih berjalan dengan sangat baik, selain itu rasio-rasio yang digunakan oleh peneliti adalah rasio yang dikaji untuk menilai kinerja keuangan lembaga yang berorientasi pada keuntungan (profit oriented) sehingga sangat tepat menggunakan rasio-rasio tersebut selain juga menggunakan rasio-rasio penilaian LPD, agar LPD Adat Demayu dapat meningkatkan kinerja keuangannya dan dapat bersaing dengan lembaga keuangan lainnya.

2. Kinerja manajemen yang ditinjau dari aspek internal mendapatkan nilai skor rata-rata keseluruhan sebesar 4,09\% yang termasuk ke dalam katagori puas sedangkan kinerja manajemen yang ditinjau dari aspek eksternal mendapatkan nilai skor rata-rata keseluruhan sebesar 4,22\% yang termasuk ke dalam katagori sangat puas. 


\subsection{Saran}

Adapun saran yang dapat penulis diberikan berdasarkan kesimpulan yang telah dibuat sebagai berikut.

1. LPD Adat Demayu kedepan agar lebih memupuk modal sendiri sehingga aktiva bertambah tanpa menambah hutang salah satunya dengan cara meningkatkan aktivitas penyaluran kredit ke masyarakat.

2. Kinerja manajemen yang ditinjau dari aspek internal sebaiknya pihak manajemen harus lebih sering berkomunikasi dan berinteraksi dengan para karyawan, untuk kinerja manajemen yang dilihat dari aspek eksternal sebaiknya pihak manajemen lebih memperhatikan dan meningkatkan kualitas pelayanan.

3. Setiap aktivitas yang dilaksanakan pada LPD Adat Demayu sebaiknya lebih ditekankan pada konsep ajaran tri hita karana.

\section{Ucapan Terima Kasih}

Ucapan terima kasih ini peneliti tujukan kepada seluruh pihak yang telah membantu dalam pelaksanaan penelitian hingga karya ilmiah ini bisa dipublikasikan dalam bentuk e-jurnal.

\section{Daftar Pustaka}

Anonim. 2012. Peraturan Daerah Provinsi Bali Nomor 4 tahun 2012 tentang Lembaga Perkreditan Desa, Pasal 22 Ayat 1 tentang Pembagian Keuntungan Lembaga Perkreditan Desa.

Anonim. 2012. Peraturan Menteri Koperasi dan UKM Republik Indonesia Nomor 06/Per/M.KUKM/V/2006 tanggal 1 Mei 2006, tentang Pedoman Penilaian Kinerja Keuangan.

Bacal, Robert. 2001. Performance Manajement (Alih Bahasa : Dharma \& irawan), Jakarta : PT. Gramedia Pustaka Utama.

Bambang, Riyanto. 1997. Dasar-dasar Pemblanjaan Perusahaan. Edisi 4. BPFE, Yogyakarta.

Mangkunegara. 2002 .Evaluasi Kinerja Sumber Daya Manusia Bandung: Refika Aditama.

Sagala, Syaiful.2006. Manajemen Strategik dalam peningkatan Mutu pendidikan. Bandung: Alfabeta.

Sakaran, Uma. 2006. Research Methods for Bisiness. Buku kedua. Jakarta: Salemba Empat.

Siregar, Sofyan. 2011. Statistik Deskriptif Untuk Penelitian. Jakarta: PT. Raja Grafindo Persada.

Singarimbun, Masri dan Sofian Effendi. 1989. Metode Penelitian Survey. LP3ES. Jakarta.

Sugiyono. 2010. Metode Penelitian Pendidikan Pendekatan Kuantitatif, Kualitatif, dan $R \& D$. Bandung : Alfabeta. 